\title{
Tauopathy in transgenic (SHR72) rats impairs function of central noradrenergic system and promotes neuroinflammation
}

\author{
Boris Mravec ${ }^{1,2^{*}}$, Katarina Lejavova ${ }^{1,2}$, Peter Vargovic ${ }^{1}$, Katarina Ondicova ${ }^{1,2}$, Lubica Horvathova ${ }^{1}$, Petr Novak ${ }^{3,4}$, \\ Georg Manz ${ }^{5}$ Peter Filipcik ${ }^{3,4}$, Michal Novak ${ }^{3,4}$ and Richard Kvetnansky ${ }^{1}$
}

\begin{abstract}
Background: Brain norepinephrine (NE) plays an important role in the modulation of stress response and neuroinflammation. Recent studies indicate that in Alzheimer's disease (AD), the tau neuropathology begins in the locus coeruleus (LC) which is the main source of brain NE. Therefore, we investigated the changes in brain NE system and also the immune status under basal and stress conditions in transgenic rats over-expressing the human truncated tau protein.

Methods: Brainstem catecholaminergic cell groups (LC, A1, and A2) and forebrain subcortical (nucleus basalis of Meynert), hippocampal (cornu ammonis, dentate gyrus), and neocortical areas (frontal and temporal association cortices) were analyzed for NE and interleukin 6 (IL-6) mRNA levels in unstressed rats and also in rats exposed to single or repeated immobilization. Moreover, gene expression of NE-biosynthetic enzyme, tyrosine hydroxylase $(\mathrm{TH})$, and several pro- and anti-inflammatory mediators were determined in the LC.

Results: It was found that tauopathy reduced basal NE levels in forebrain areas, while the gene expression of IL-6 was increased in all selected areas at the same time. The differences between wild-type and transgenic rats in brain NE and IL-6 mRNA levels were observed in stressed animals as well. Tauopathy increased also the gene expression of TH in the LC. In addition, the LC exhibited exaggerated expression of pro- and anti-inflammatory mediators (IL-6, TNFa, inducible nitric oxide synthases 2 (iNOS2), and interleukin 10 (IL-10)) in transgenic rats suggesting that tauopathy affects also the immune background in LC. Positive correlation between NE and IL-6 mRNA levels in cornu ammonis in stressed transgenic animals indicated the reduction of anti-inflammatory effect of NE.

Conclusions: Our data thus showed that tauopathy alters the functions of LC further leading to the reduction of NE levels and exaggeration of neuroinflammation in forebrain. These findings support the assumption that tau-related dysfunction of LC activates the vicious circle perpetuating neurodegeneration leading to the development of AD.
\end{abstract}

Keywords: Alzheimer's disease, Locus coeruleus, Neuroinflammation, Stress, Tauopathy, Transgenic rats

\section{Background}

Sporadic Alzheimer's disease (AD) represents the most prevalent form of dementia in the elderly, with several hypotheses being proposed to explain its etiopathogenesis. These hypotheses have focused either on the role of amyloid $\beta$, hyperphosphorylated and truncated tau protein,

\footnotetext{
* Correspondence: boris.mravec@savba.sk

1 Institute of Experimental Endocrinology, Slovak Academy of Sciences,

Vlarska 3, 83306 Bratislava, Slovakia

${ }^{2}$ Institute of Physiology, Faculty of Medicine, Comenius University in

Bratislava, Bratislava, Slovakia

Full list of author information is available at the end of the article
}

neuroinflammation, altered insulin signalization, impaired blood-brain barrier permeability, or other related factors and mechanisms $[1,2]$. However, despite such enormous scientific effort, the primary factors responsible for the development of $\mathrm{AD}$ still remain only vaguely defined.

Recently accumulated evidence indicates that alteration of the brain's noradrenergic system plays an important role in the development of AD-related neuropathology during the early stages of AD. Central norepinephrine (NE)-synthesizing neurons are located predominantly in the brainstem, particularly in the locus 
coeruleus (LC). These neurons richly ramify and innervate structures throughout the neuraxis, providing NE to all brain and spinal cord structures [3]. NE released from these neurons reduces neuroinflammation and potentiates synaptic plasticity and neurogenesis. In addition, NE modulates energy metabolism, the activity of astrocytes and microglia, cortical perfusion, and permeability of the blood-brain barrier [4-7]; all functions impaired in $\mathrm{AD}$ patients. Moreover, recent findings indicate that tau pathology initially occurs in specific brainstem nuclei, particularly the LC, and spreads from these nuclei to the forebrain [8-10]. Therefore, it has been suggested that the $\mathrm{LC}$ may represent the center of $\mathrm{AD}$-related neuropathology [11].

Based on the abovementioned facts, we investigated the interrelations between brain NE and markers of neuroinflammation in discrete brain areas of both wild-type as well as in transgenic (SHR72) rats expressing a pathological form of tau protein at basal conditions. However, since brain NE-synthesizing neurons are activated during stress, which is implicated in the development of $\mathrm{AD}$ [12-15], we also investigated the effect of both single and repeated immobilization (IMO) stress on NE and interleukin 6 (IL-6) mRNA levels in brain structures known to be involved in $\mathrm{AD}$ neuropathology. In our study, we focused on brainstem catecholaminergic cell groups (LC, A1, A2) as well as the forebrain structures innervated by the LC, including cornu ammonis (CA), dentate gyrus (DG), nucleus basalis of the Meynert (NBM), and both frontal (FCx) and temporal (TCx) association cortices. In addition, in the LC, we analyzed gene expression of the NE-biosynthetic enzyme, and tyrosine hydroxylase $(\mathrm{TH})$, as well as several pro- and antiinflammatory mediators.

\section{Methods}

\section{Animals}

Experiments were performed on 6-month-old male transgenic (SHR72) and age-matched wild-type rats of the same SHR genetic background. The transgenic (SHR72) animals expressed a fragment of tau protein containing four C-terminal repeats designed to correspond with the pathological tau protein found in human AD brains. The transgenic (SHR72) animals were prepared by microinjection of human cDNA encoding $\mathrm{N}$ - and C-terminal truncated tau protein encompassing the region of amino acids 151-391 into the male pronucleus of 1-day-old rat embryos. The transgenic construct (human truncated MAPT cDNA under Thy-1 promoter) was devoid of all prokaryotic sequences before injection. The injected embryos were incubated in vitro and implanted to the oviducts of pseudopregnant foster mothers about $12 \mathrm{~h}$ after the injection. This animal model recapitulates basic features of human neurofibrillary pathology typical of $\mathrm{AD}$ sufferers and is the unique transgenic model that unequivocally demonstrates that expression of pathologically truncated tau protein is sufficient to drive neuropathology typical of $\mathrm{AD}$ [16-18].

The homozygous transgenic (SHR72) animals with eight copies of the transgene per genome only survived to the age of 4 months. Therefore, we bred hemizygous transgenic (SHR72) animals with wild-type animals of the same genetic background, which expanded the lifespan of transgenic (SHR72) animals to an average of 7 months. The transgene was transmitted to subsequent generations according to Mendelian law, and the colony was phenotypically stable at the time the animals used in this study were taken (12th generation).

The animals, bred at the Institute of Neuroimmunology, were kept under controlled conditions in the animal facility (12-h light/12-h dark cycle, lights on/off at 0600 hours; temperature, $22 \pm 1{ }^{\circ} \mathrm{C}$ ) with free access to tap water and standard pelleted rat chow. All experiments were performed between 0800 and 1200 hours, with all external noises or any other stressful stimuli of the animals being strictly avoided. The experiments were carried out in accordance with the Council Directive 2010/63EU of the European Parliament and the Council of 22 September 2010 on the protection of animals used for scientific purposes.

\section{Immobilization stress}

In the experiments, we used unstressed (control) and stressed groups of wild-type and transgenic (SHR72) rats (Fig. 1):

(a) Control groups (C): unstressed animals ( $n=9$ of both wild-type and transgenic rats) that were decapitated immediately after being taken out from their home cages.

(b) Single IMO group ( $1 \times \mathrm{IMO})$ : the animals ( $n=9$ of both wild-type and transgenic rats) that were subjected once to $2 \mathrm{~h}$ IMO and were decapitated immediately after the end of stressor exposure.

(c) Repeated IMO group $(7 \times \mathrm{IMO})$ : the animals $(n=10$ of both wild-type and transgenic rats) were subjected repeatedly to IMO for $2 \mathrm{~h}$ daily for seven successive days and decapitated immediately after the last IMO was finished.

(d)Adapted IMO group $(6 \times \mathrm{IMO}+24 \mathrm{~h})$ : the animals ( $n=10$ of both wild-type and transgenic rats) were subjected to IMO for $2 \mathrm{~h}$ daily for six successive days and decapitated $24 \mathrm{~h}$ after the last IMO, at the time when the seventh IMO would have been finished. This group enables to determine the effect of seventh exposure to IMO in repeatedly stressed rats and therefore to investigate the mechanisms of adaptation to chronic stress. The IMO stress was performed as previously described [19]. 


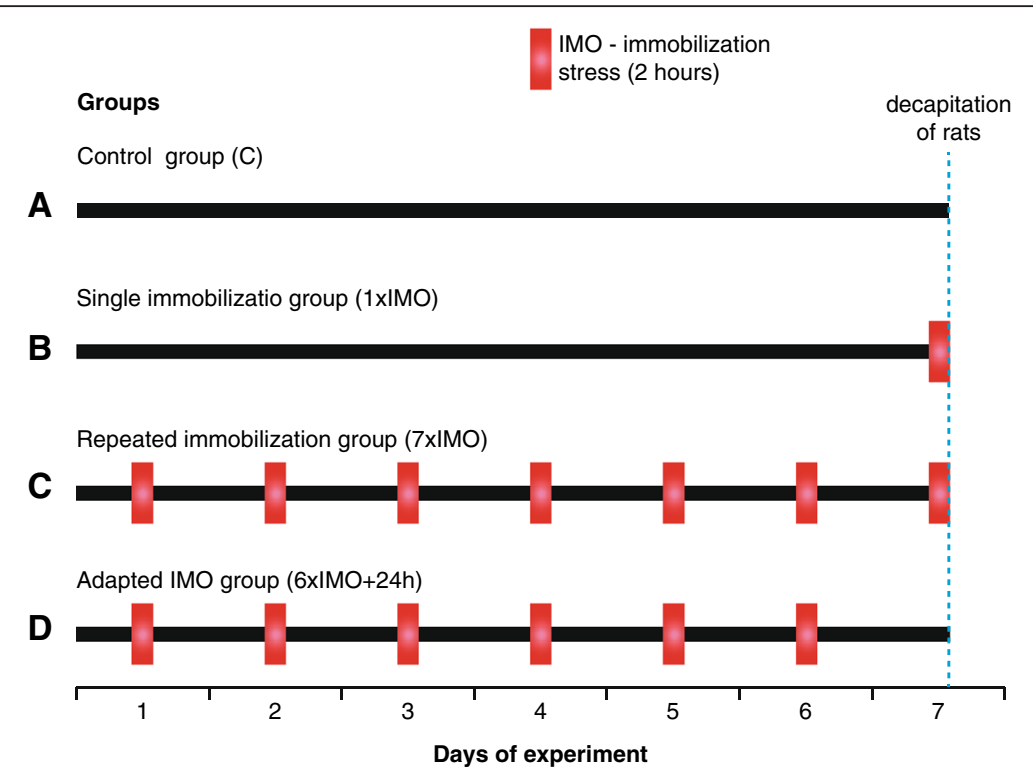

Fig. 1 Schematic illustration of experimental design. a Control group. b Single immobilization group (1XIMO). c Repeated immobilization group (7XIMO). d Adapted IMO group (6xIMO+24 h)

\section{Microdissection of brain areas}

The tissue of brainstem catecholaminergic cell groups as well as that of the forebrain subcortical and cortical areas (Fig. 2) was dissected bilaterally by the micropunch technique [20] according to the original punching guide atlas [21]. Briefly, after the quick removal, the brains were immediately frozen on dry ice and cut into 300- $\mu \mathrm{m}$-thick serial coronal sections using a cryostat (Reichert-Jung) at $-10{ }^{\circ} \mathrm{C}$. The tissue was isolated under a dissection microscope by specialized metal punching needles with a diameter ranging from 600 to $1200 \mu \mathrm{m}$ (for details, see Fig. 2) and then stored at $-70{ }^{\circ} \mathrm{C}$ for the later analyses.

\section{Determination of catecholamine in brain areas}

Tissues of isolated brain areas were sonicated in $100 \mu \mathrm{L}$ of $0.01 \mathrm{M} \mathrm{HCl}$. Two microliters of homogenate were used for the determination of proteins using a bicinchoninic acid (BCA) protein assay (Thermo Scientific, Rockford, IL.). The appropriate amount of supernatant (containing $10-400 \mu \mathrm{g}$ of protein, depending on brain area) was used for norepinephrine measurement using 3-CAT Research RIA kits (Labor Diagnostica Nord, Nordhorn, Germany) according to the manufacturer's protocol. We have tested this method for different brain areas, and we obtained a good linearity of measurements between 10 and $800 \mathrm{pg}$ of NE or 10 and $400 \mu \mathrm{g}$ protein in homogenates. The final loading amounts of homogenates were LC and NBM, 10-20 $\mu \mathrm{g}$ of protein; A1 and A2 noradrenergic cell groups, $20-30 \mu \mathrm{g}$ of protein; temporal cortex, 100-200 $\mu \mathrm{g}$ of protein; frontal cortex, 300-400 $\mu \mathrm{g}$ of protein; and CA, $300-400 \mu \mathrm{g}$ of protein. The sensitivity of the RIA assay for NE in the brain tissue was $7.2 \mathrm{pg} /$ sample making it sensitive enough for the performed experiments. The values were normalized to proteins determined in the homogenate and expressed as nanograms of catecholamine per milligram of protein.

\section{Isolation of RNA and measurement of mRNA levels by RT-PCR}

Total RNA was isolated from the frozen tissue samples of the brain areas using TRI REAGENT (MRC, Inc.). Reverse transcription was performed from total RNA using Ilustra $^{\mathrm{Tm}}$ Ready-To-Go ${ }^{\mathrm{Tm}}$ RT-PCR beads (GE Healthcare, Buckinghamshire, UK) with $\operatorname{pd}(\mathrm{N})_{6}$ primer according to manufacturer's protocol.

Gene expression was determined by RT-PCR analyses. For all PCR amplifications, cDNA aliquots containing 20 ng of total RNA were used. Transcripts were amplified with specific primers (shown in Table 1) using a SensiFast Hi-ROX qPCR Kit (Bioline, Taunton, MA) according to the manufacturer's instructions in $20 \mu \mathrm{L}$ of total reaction volume using an ABI Prism 7900HT Sequence Detection System thermocycler (Applied Biosystems, Inc, Foster City, CA, USA). Data were analyzed with sodium dodecyl sulfate (SDS) software version 2.3 (Applied Biosystems) and inspected to determine artifacts (loading errors, threshold errors, etc.). Count numbers (Ct values) were exported to an Excel spreadsheet and analyzed according to the $\Delta \Delta C T$ method described by Livak and Schmittgen [22]. For internal controls, several genes were tested including $18 \mathrm{~S}$ rRNA, beta tubulin, GAPDH, TATA-binding protein, RPS21, and beta actin. We normalized the results 


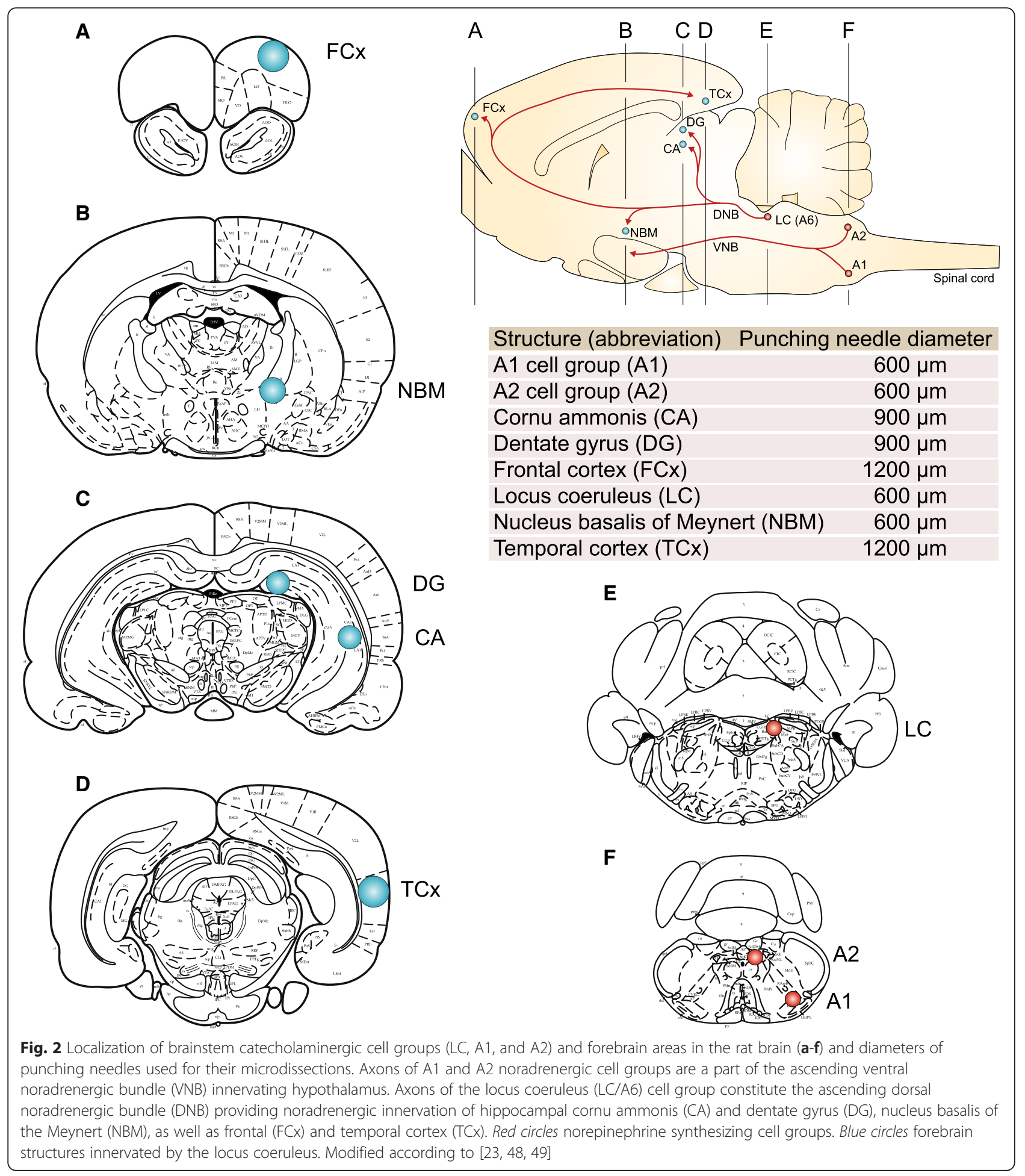

of the investigated genes to these internal controls and found similar results regarding both gene expression changes and patterns. Subsequently, we examined the variability of values between samples within experimental groups and concluded that $18 \mathrm{~S}$ rRNA would be the most appropriate internal control.

\section{Western blot analysis}

For detection of TH protein, freshly frozen brain samples were homogenized in ice-cold extraction buffer (20 mM Tris- $\mathrm{HCl}, \mathrm{pH} 8,100 \mathrm{mM} \mathrm{NaCl}, 1 \mathrm{mM}$ EDTA, $1 \mathrm{mM}$ dithiothreitol, $0.5 \%$ Triton X-100, $20 \mathrm{mM} \mathrm{NaF}$, and $1 \mathrm{mM}$ activated $\mathrm{Na}_{3} \mathrm{VO}_{4}$ ) supplemented with protease 
Table 1 Sequences of primers used for amplification of target cDNA of interleukin 6 (IL-6), tyrosine hydroxylase (TH), tumor necrosis factor alpha (TNF-a), inducible nitric oxide synthases 2 (iNOS2), interleukin 10 (IL-10), transforming growth factor beta 1 (TGF 1 1), and $18 \mathrm{~S}$ ribosomal protein

\begin{tabular}{lll}
\hline Gene & Primer & Oligonucleotide sequence \\
\hline IL-6 & Forward & AAGTCGGAGGCTTAATACATATGTTC \\
& Reverse & TCATCGCTGTCATACAATCAGAA \\
TH & Forward & TCTCCCTGAGGGGTACAAAA \\
& Reverse & GAATTTGGCTTCAAATGTCTCA \\
TNF-a & Forward & TGATCGGTCCCAACAAGGA \\
& Reverse & TGGGCTACGGGCTTGTCA \\
iNOS2 & Forward & GCTTCAGAATGGGGAGTG \\
& Reverse & AGGTTGAGGCCTTGTGTC \\
IL-10 & Forward & CCCTGGGAGAGAAGCTGAAGA \\
& Reverse & CACTGCCTTGCTITATTCTCACA \\
TGF 31 & Forward & CCTGGAAAGGCTCAACAC \\
& Reverse & CAGTCTTCTCTGTGGAGCTGA \\
18S & Forward & ATGGTCCTITGTCGCTCGCTCC \\
& Reverse & TGGATGTGGTAGCCGTTCTCAGG \\
\hline
\end{tabular}

inhibitor cocktail (Complete without EDTA; Roche, Manheim, Germany) using the disposable polypropylene homogenizers fitted to the tip of $1.5 \mathrm{~mL}$ eppendorf tube (E\&K Scientific Products, CA, USA). The samples were centrifuged for $20 \mathrm{~min}$ at $16,000 \times g$, and supernatants were transferred into new tubes. Concentrations of total proteins were measured by PierceTM BCA protein assay kit (Thermo Scientific, USA). Samples were mixed with standard $2 \times$ sample loading buffer $(10 \mathrm{mM}$ Tris- $\mathrm{HCl}, 4 \%$ SDS, $4 \%$ 2-mercaptoethanol, $20 \%$ glycerol, and $0.1 \%$ Coomassie Brilliant Blue G-250) and heated at $95{ }^{\circ} \mathrm{C}$ for $5 \mathrm{~min}$. Twenty micrograms of total protein was then separated by electrophoresis in $12 \%$ SDS-polyacrylamide gels. Separated proteins were transferred onto nitrocellulose membranes (Whatman, Maidstone, UK), which were blocked in Odyssey blocking buffer (LI-COR, Lincoln, NE, USA) containing $0.1 \%$ Tween 20 (Sigma, St. Louis, MO, USA). Membranes were incubated overnight with primary monoclonal antibody (anti-TH, MAB5280, Millipore, dilution 1:3000) in Odyssey blocking buffer (LI-COR, Lincoln, NE, USA) containing $0.1 \%$ Tween 20 (Sigma, St. Louis, MO, USA). Secondary infrared $800 \mathrm{CW}$ goat anti-mouse IgG (LI-COR, Lincoln, NE, USA) was diluted 1:10,000 in Odyssey blocking buffer (LI-COR, Lincoln, NE, USA) containing $0.1 \%$ Tween 20 (Sigma, St. Louis, MO, USA) and incubated with membrane for $2 \mathrm{~h}$ at RT. The blots were scanned with Odyssey infrared imaging system (LI-COR, Lincoln, NE, USA). Detected bands were quantified using Image Studio software ver. 2.0.38 (LI-COR, Lincoln, NE, USA).

\section{Statistical analysis}

All statistical analyses were performed using SigmaPlot 11.0 (Systat Software, Inc., Germany). The normal distribution of the quantitative data was verified for all analyzed data using the Kolmogorov-Smirnov test allowing for parametric tests to be applied. Statistical analysis of the data was performed by $t$ test (used for the comparison of changes in NE and IL-6 mRNA levels between unstressed wild-type and transgenic rats; Fig. 3) and by one-way ANOVA measurement followed by a Dunnett's test (used for the comparison of changes in NE levels as well as in mRNA levels of $\mathrm{TH}$ and cytokines in rats exposed to a single or repeated immobilization; Figs. 4, $5,6,7$, and 8). The correlation between NE levels and IL-6 mRNA levels was determined by linear regression test (Fig. 9). The results are expressed as means \pm SEM and represent an average of four to ten animals. A $P$ value of $<0.05$ was taken as indicative of statistical significance for the tests.

\section{Results \\ Effect of tauopathy on basal norepinephrine and IL-6 mRNA levels in brainstem and forebrain areas}

Tauopathy significantly affected basal levels of NE as well as gene expression of IL-6, one of the major proinflammatory cytokines in the brain (Fig. 3). Although NE levels were not considerably changed in the brainstem catecholaminergic cell groups, they were clearly decreased in all forebrain structures innervated by the $\mathrm{LC}$, particularly in hippocampal areas such as the CA and DG, as well as NBM, FCx, and TCx in transgenic (SHR72) animals compared to wild-type rats $(P<0.05$; Fig. 3a). On the other hand, basal levels of IL-6 mRNA were elevated in all abovementioned investigated areas, the most prominent elevation being observed in the LC and DG of transgenic rats $(P<0.01$; Fig. $3 b)$.

These data led us to further study the question of whether the tauopathy itself affects NE and IL6 mRNA levels in the investigated brain areas of transgenic rats under the conditions of single and repeated stress by immobilization.

\section{Effect of tauopathy on stress-induced changes of norepinephrine levels in brainstem and forebrain areas} We found that in stressed rats, there were differences in NE levels within selected brain structures between the wild-type and transgenic groups. In general, in stressed transgenic rats, the concentrations of NE remained unchanged compared to their unstressed, transgenic controls.

In the LC, a significant reduction of NE concentration was found in wild-type animals exposed to either single or repeated IMO $(P<0.05$; Fig. 4 a). However, transgenic animals did not show this stress-induced reduction in NE levels (Fig. 4a). Furthermore, we did not find any 


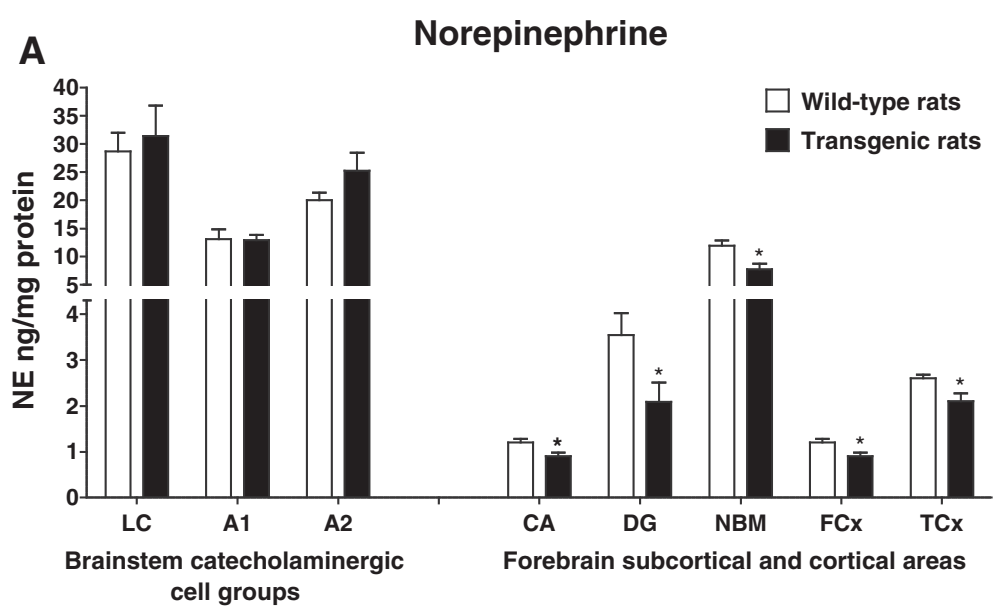

B

IL-6 mRNA

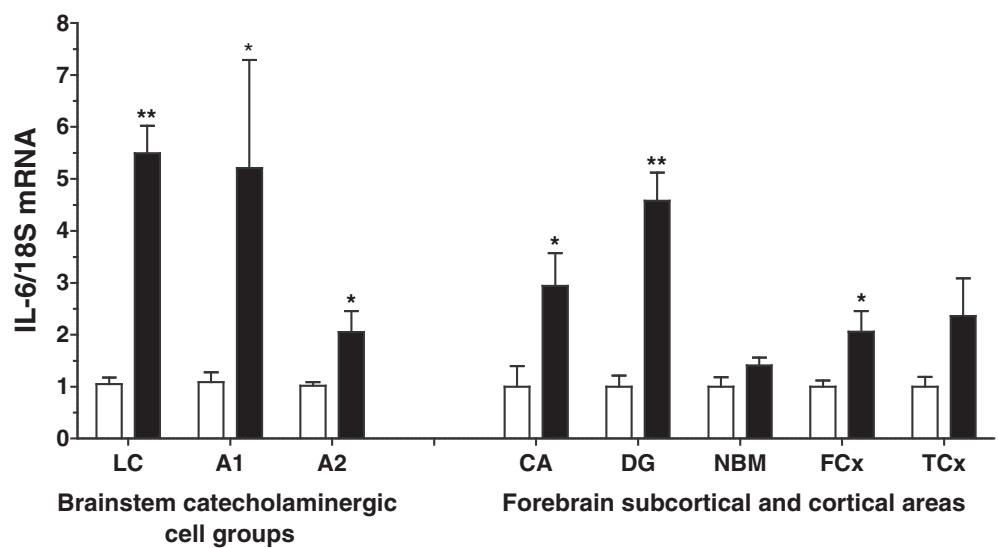

Fig. 3 Basal levels of norepinephrine (NE) and interleukine-6 mRNA (IL-6 mRNA) in brainstem catecholaminergic cell groups containing NE cell bodies (LC, A1, A2) and forebrain subcortical and cortical areas in wild-type (white square) and transgenic (SHR72) rats (black square). Each value is the mean \pm SEM $(n=4-10)$. Statistical significance vs. corresponding wild-type group: ${ }^{*} P<0.05 ;{ }^{*} P<0.01$

significant changes in NE concentrations within the A1 noradrenergic cell group when examining singly or repeatedly stressed wild-type and transgenic rats (Fig. 4c). But, the A2 noradrenergic cells group showed a nonsignificant reduction in NE levels in both wild-type and transgenic animals exposed to single IMO (Fig. 4e).

We found that NE levels were reduced in both hippocampal regions (CA and DG) compared to wild-type animals in both the single $(P<0.01)$ and repeatedly stressed $(P<0.01)$ transgenic rats as well as in transgenic rats from the adapted IMO group $(P<0.05)$. Whereas repeated IMO non-significantly increased NE levels in the CA and DG of wild-type rats the NE levels remained unchanged or were even non-significantly reduced in transgenic rats when compared to controls (Fig. 5a, c).

Although we have seen significantly reduced NE levels in the FCx of transgenic compared to wild-type rats $(P<0.01$, single and repeatedly stressed rats; $P<0.05$, adapted IMO rats; Fig. 6a), we found no difference in the levels of NE levels in the TCx between stressed transgenic and wild-type rats (Fig. 6c). Whereas repeated stress non-significantly increased $\mathrm{NE}$ levels in the $\mathrm{FCx}$ of wild-type rats, NE levels did not change or were even non-significantly reduced in transgenic rats when compared to controls. Additionally, NE levels in the TCx were unchanged, while reduced NE levels were found in the entorhinal cortex (data not shown).

Repeated stress non-significantly increased NE levels in the NBM of wild-type rats. In transgenic rats, NE levels remained unchanged when compared to those of unstressed transgenic animals, but they were significantly lower than these in repeatedly stressed wild-type rats $(P<0.01$; Fig. 6e).

Effect of tauopathy on stress-induced changes of IL- 6 mRNA levels in brainstem and forebrain areas

Both, single as well as repeated exposure to IMO stress induced a significant elevation of IL-6 mRNA level in 


\section{Locus coeruleus}
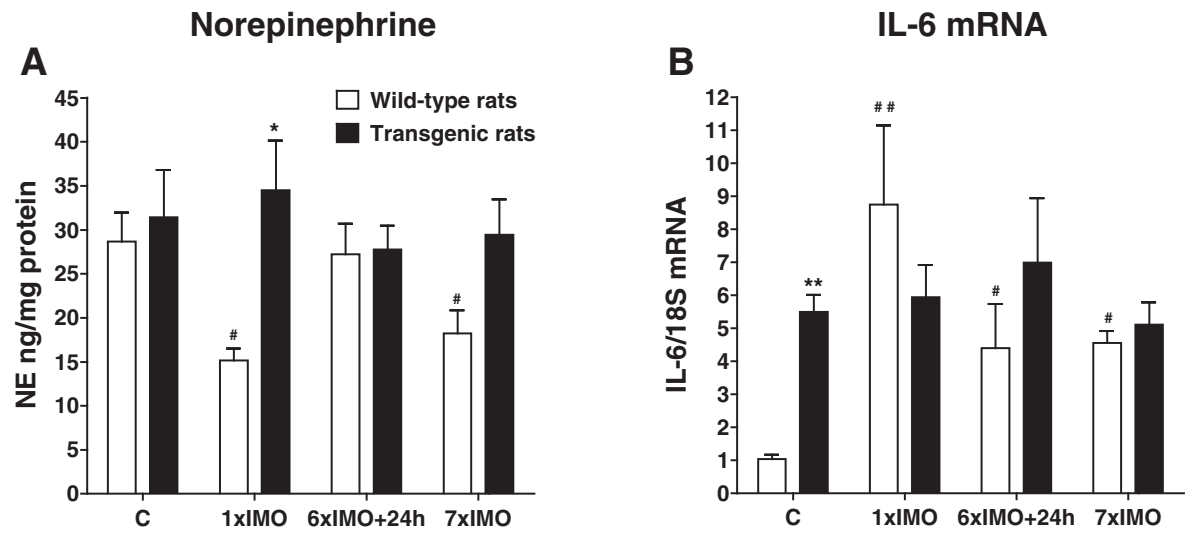

A1 cell group
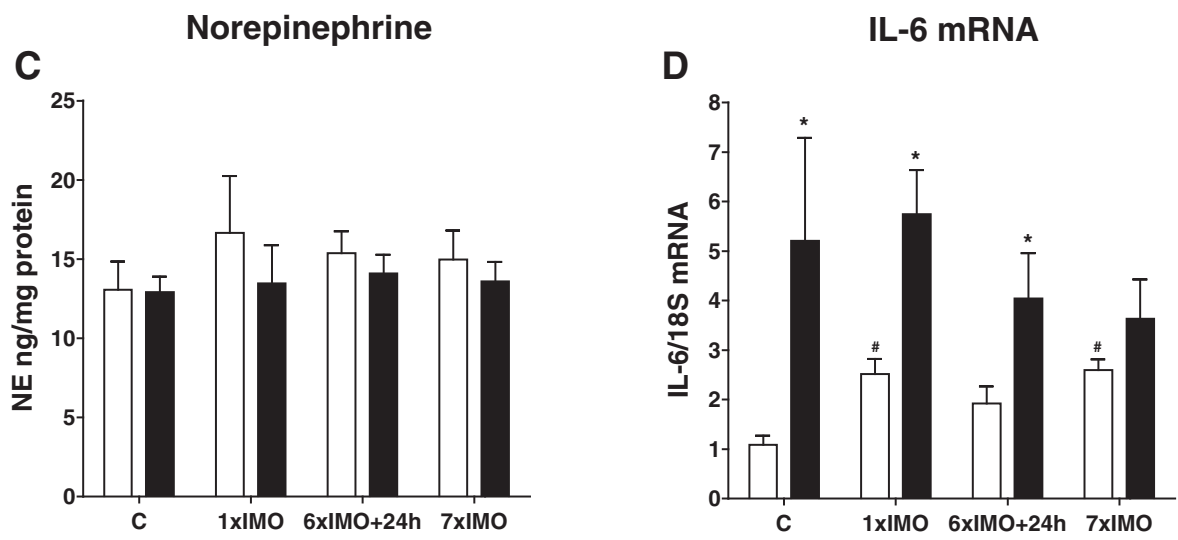

A2 cell group
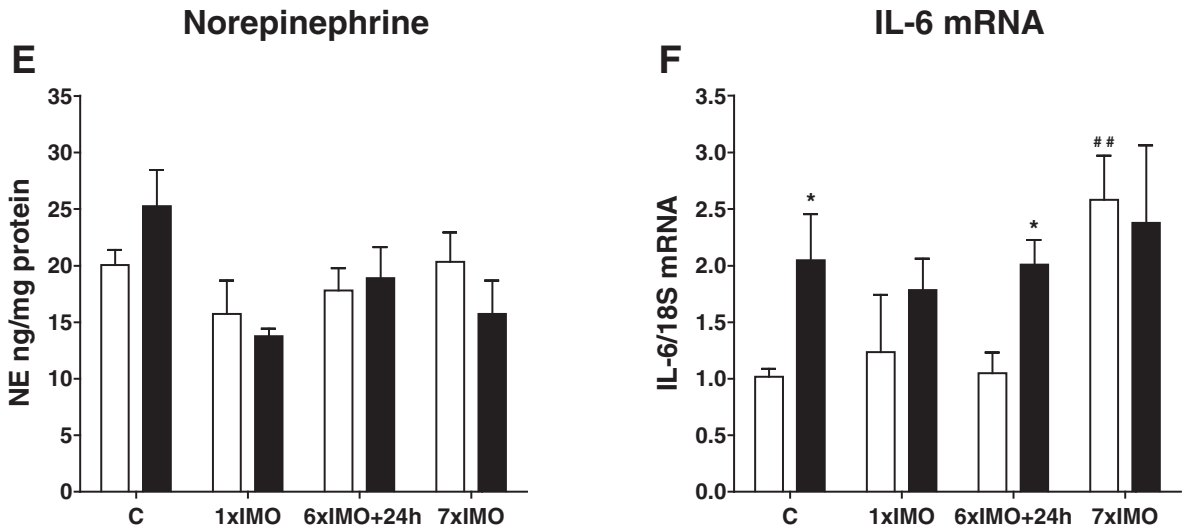

Fig. 4 Levels of norepinephrine (NE) and interleukine-6 mRNA (IL-6 mRNA) in the LC, A1, and A2 brainstem noradrenergic areas in wild-type (white square) and transgenic (SHR72) rats (black square) exposed to a single $(1 \times 2 \mathrm{~h})$ or repeated $(7 \times 2 \mathrm{~h})$ immobilization stress (IMO). C control rats; $6 \times 1 M O+24 \mathrm{~h}$-adapted IMO rats exposed to $6 \times 1 \mathrm{MO}$ for $2 \mathrm{~h}$ and decapitated $24 \mathrm{~h}$ after the last IMO. Each value is the mean \pm SEM $(n=5-8)$. Statistical significance vs. corresponding wild-type group: ${ }^{*} P<0.05$; ${ }^{* *} P<0.01$; statistical significance vs. wild-type control group: ${ }^{\#} P<0.05$; ${ }^{\# \# P}<0.01$ 


\section{Cornu ammonis}
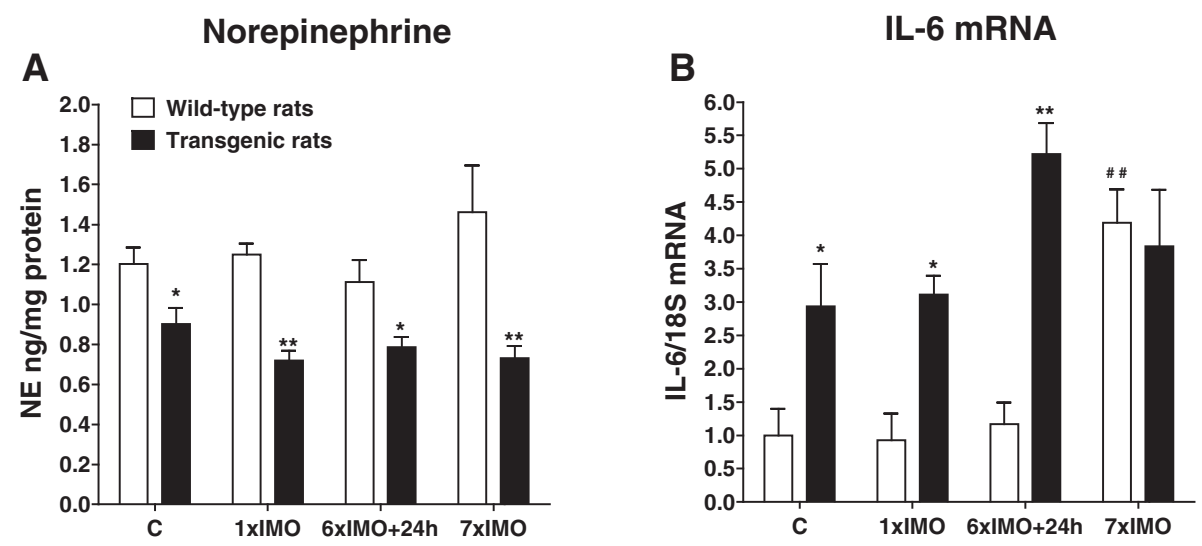

Dentate gyrus
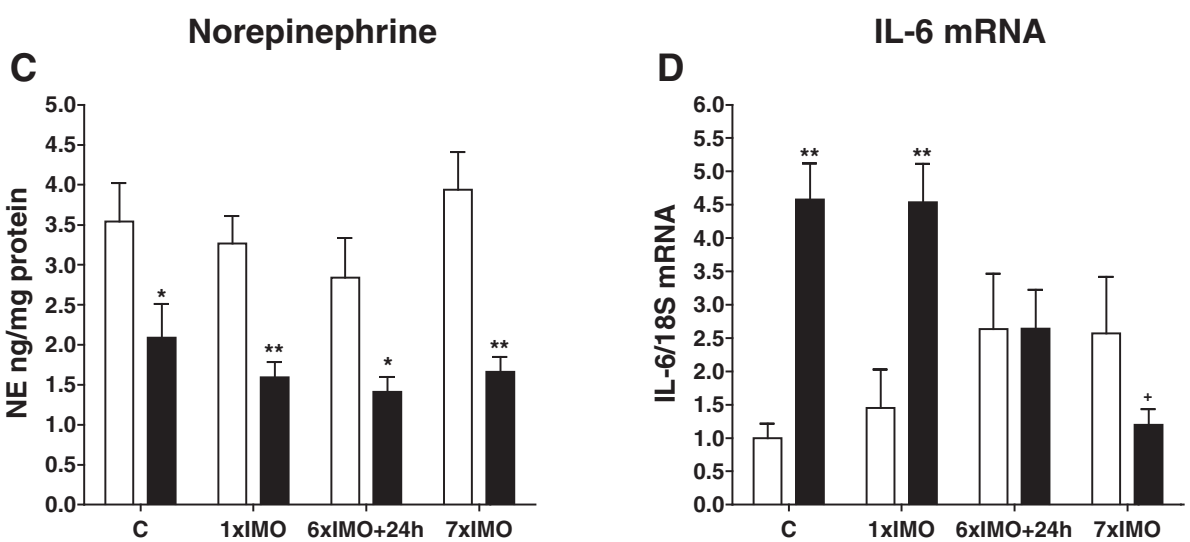

Fig. 5 Levels of norepinephrine (NE) and interleukine-6 mRNA (IL-6 mRNA) in the cornu ammonis (CA) and dentate gyrus (DG) in wild-type (white square) and transgenic (SHR72) rats (black square) exposed to a single $(1 \times 2 \mathrm{~h})$ or repeated $(7 \times 2 \mathrm{~h})$ immobilization stress (IMO). C control; $6 \times 1 \mathrm{MO}+24 \mathrm{~h}$-adapted $\mathrm{IMO}$ rats exposed to $6 \times \mathrm{IMO}$ for $2 \mathrm{~h}$ and decapitated $24 \mathrm{~h}$ after the last IMO. Each value is the mean \pm SEM $(n=5-8)$. Statistical significance vs. corresponding wild-type group: ${ }^{*} P<0.05$; ${ }^{*} P<0.01$; statistical significance vs. wild-type control group: ${ }^{\#} P<0.05$; ${ }^{\# \#} P<0.01$; statistical significance vs. transgenic control group: ${ }^{+} P<0.05$

the LC $(P<0.01$, single stress; $P<0.05$; adapted IMO and repeated stress; Fig. $4 \mathrm{~b})$ and A1 noradrenergic cell group $(P<0.05$ single and repeated stress; Fig. $4 \mathrm{~d})$ of wild-type animals, However, IL-6 mRNA levels were only elevated in wild-type animals by repeated stress in the A2 noradrenergic cell group $(P<0.01$; Fig. $4 \mathrm{f}), \mathrm{CA}$ $(P<0.01$; Fig. 5b), and FCx $(P<0.05$; Fig. 6b).

Similar to the abovementioned findings of NE levels in stressed transgenic rats, exposure of rats to IMO did not induce further increases in IL-6 gene expression in selected brain areas of transgenic animals when compared to values found in unstressed transgenic animals (Figs. 4, 5 , and 6). However, in some brainstem and in hippocampal areas, IL-6 mRNA levels were significantly elevated in stressed transgenic rats compared to corresponding wild-type groups (Figs. 4d, e, and 5b, d).
Effect of tauopathy on basal and stress-induced changes of TH gene expression and TH protein levels in brainstem noradrenergic cell groups

Brainstem noradrenergic neurons, particularly these in the LC, provide NE to all levels of the neuraxis. Reduced NE levels and increased levels of IL-6 mRNA in investigated forebrain structures (Fig. 3a, b) indicate altered function of brainstem noradrenergic neurons. Therefore, when attempting to assess the functionality of the LC, we selected TH mRNA and protein levels as markers of NE synthesis. We also investigated the effect of stress on gene expression and protein levels of $\mathrm{TH}$.

Repeated IMO significantly increased TH mRNA levels in LC of wild-type rats $(P<0.05$; Fig. $7 \mathrm{a})$. This is not surprising as $\mathrm{TH}$ gene expression in the LC of 


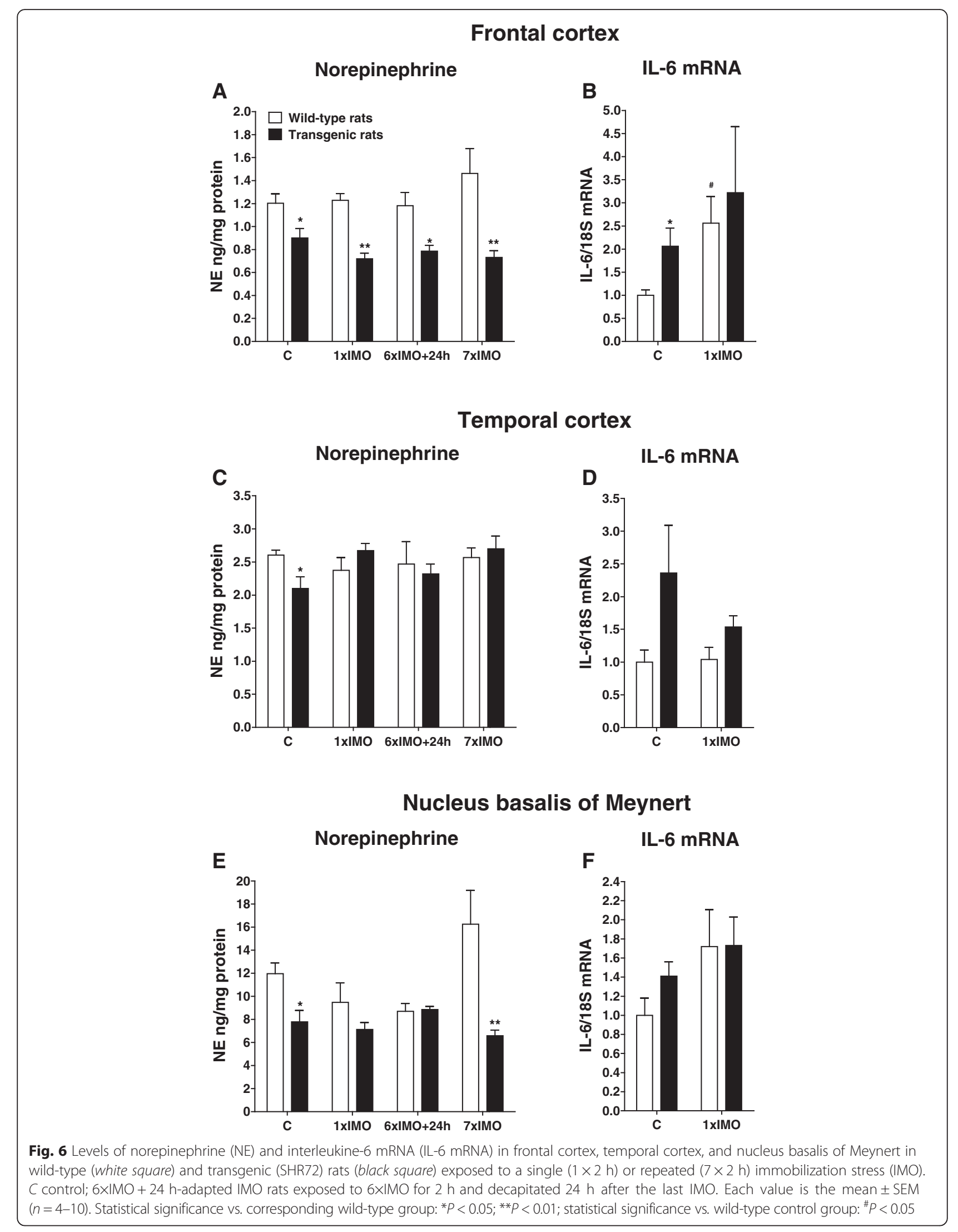




\section{Locus coeruleus}

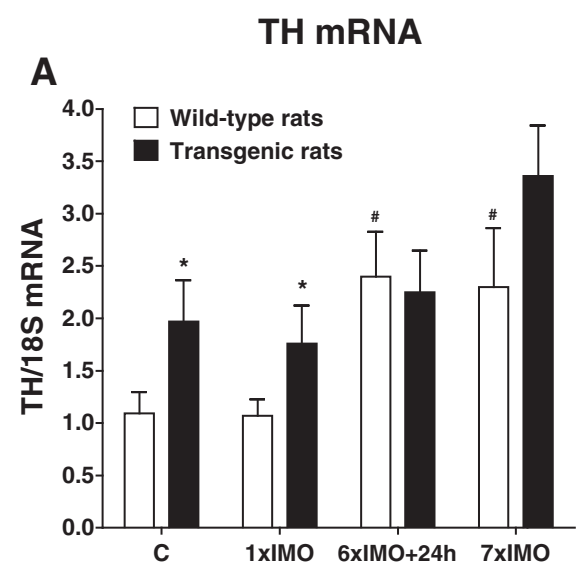

Locus coeruleus

TH protein

C

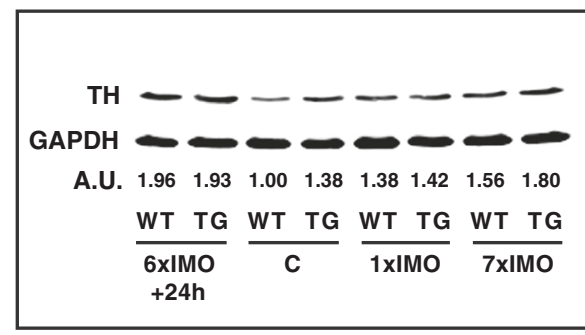

A1 cell group

TH mRNA

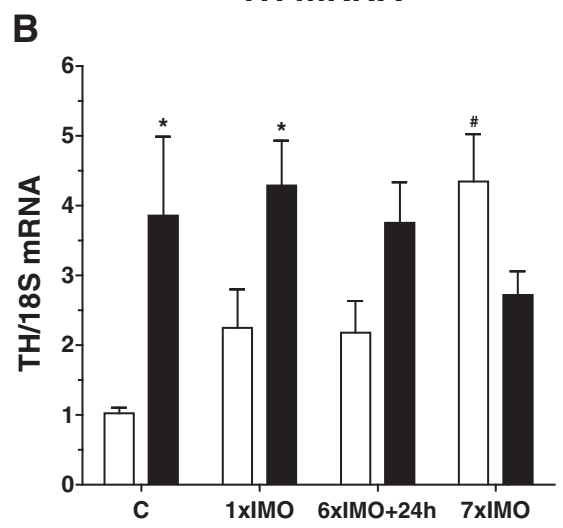

A2 cell group

TH mRNA

D

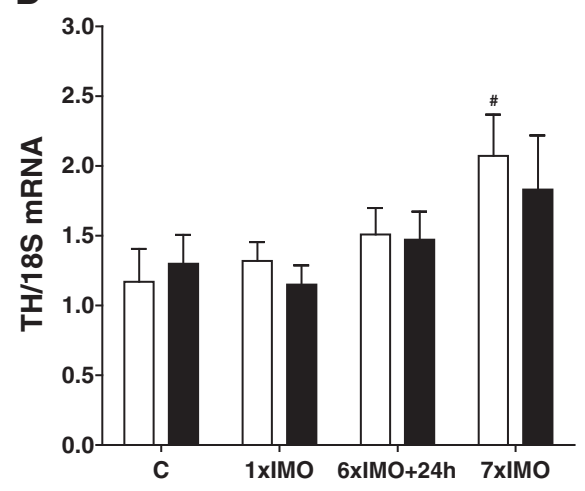

Fig. 7 Gene expression ( $\mathbf{a}, \mathbf{b}$, and $\mathbf{d}$ ) and protein (c) levels of tyrosine hydroxylase (TH) in the LC, A1, and A2 brainstem noradrenergic cell groups of wild-type (white square) and transgenic (SHR72) rats (black square) exposed to a single $(1 \times 2 \mathrm{~h})$ or repeated $(7 \times 2 \mathrm{~h})$ immobilization stress (IMO). Each sample of TH protein represents a pool of two to three animals (c), values are expressed as arbitrary units (A.U.) calculated as a ratio between TH and GAPDH in a given sample. C control; 6xIMO $+24 \mathrm{~h}$-adapted IMO rats exposed to $6 \times 1 \mathrm{MO}$ for $2 \mathrm{~h}$ and decapitated $24 \mathrm{~h}$ after the last IMO. Each value is the mean \pm SEM $(n=5-8 ; \mathbf{a}, \mathbf{b}$, and $\mathbf{d})$. Statistical significance vs. corresponding wild-type group: ${ }^{*} P<0.05$; statistical significance vs. wild-type control group: ${ }^{\#} P<0.05$

transgenic rats was already significantly increased in unstressed $(P<0.05)$ as well as in singly stressed transgenic rats when compared to corresponding wild-type animals $(P<0.05$; Fig. 7a). Also, non-significantly increased $\mathrm{TH}$ mRNA levels were observed in repeatedly stressed transgenic rats (Fig. 7a). These stress-induced increases of $\mathrm{TH}$ in transgenic rats were confirmed by similar results found in $\mathrm{TH}$ protein levels (Fig. 7c).

We also investigated $\mathrm{TH}$ gene expression in the $\mathrm{A} 1$ and A2 noradrenergic cell groups. We found that $\mathrm{TH}$ mRNA levels in the A1 noradrenergic cell group of wildtype animals were significantly elevated only by repeated IMO stress $(P<0.05$; Fig. $7 \mathrm{~b})$. When compared to wild- type animals, transgenic rats showed elevated basal levels $(P<0.05)$, but no further elevation was detected after either single or repeated stress (Fig. 7b). Similarly to the A1 noradrenergic cell group, gene expression of $\mathrm{TH}$ in the A2 noradrenergic cell group of wild-type animals was significantly elevated only by repeated IMO stress $(P<0.05$; Fig. $7 d)$.

In transgenic rats, stress did not induce any significant changes in TH mRNA levels. Similarly, no changes were seen when comparing the values of TH mRNA levels in the A2 noradrenergic cell groups between transgenic rats and corresponding wild-type animals (Fig. 7d). 


\section{Locus coeruleus}
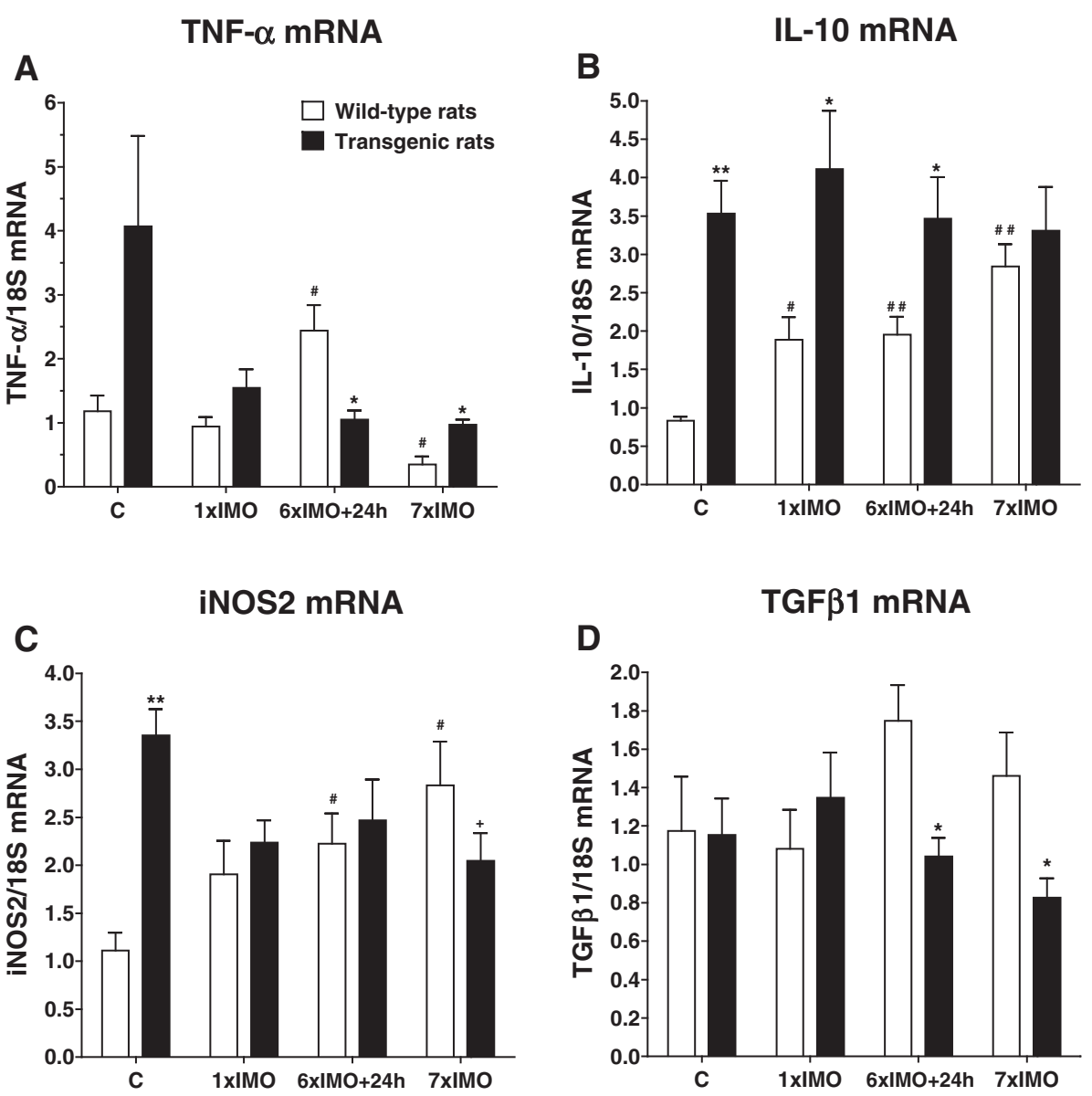

Fig. 8 Gene expression of pro-inflammatory factors TNF-a (a), iNOS2 (c), and anti-inflammatory factors IL-10 (b) and TGF $\beta 1$ (d) in the LC of wild-type (white square) and transgenic (SHR72) rats (black square) exposed to a single $(1 \times 2 \mathrm{~h})$ or repeated $(7 \times 2 \mathrm{~h})$ immobilization stress (IMO). C control; $6 \times 1 M O+24 \mathrm{~h}$-adapted IMO rats exposed to 6 XIMO for $2 \mathrm{~h}$ and decapitated $24 \mathrm{~h}$ after the last IMO. Each value is the mean \pm SEM $(n=5-8)$. Statistical significance vs. corresponding wild-type group: ${ }^{*} P<0.05$; ${ }^{* *} P<0.01$; statistical significance vs. wild-type control group: ${ }^{\#} P<0.05,{ }^{\# \#} P<0.01$

Effect of tauopathy on basal and stress-induced changes of levels of pro- and anti-inflammatory factors in the locus coeruleus

In transgenic rats, tauopathy is localized mainly to the brainstem [16]. Because tauopathy also induces neuroinflammation, we also investigated levels of selected proand anti-inflammatory factors as markers of the immune milieu of the LC.

Besides IL- 6 mRNA, we determined in the LC expression of genes of other inflammatory factors, particularly the tumor necrosis factor alpha (TNF- $\alpha$ ), inducible nitric oxide synthases 2 (iNOS2), interleukin 10 (IL-10), and transforming growth factor beta 1 (TGF $\beta 1$ ). Whereas mRNA levels of the pro-inflammatory factor TNF- $\alpha$ were only non-significantly elevated in unstressed transgenic rats $(P=0.078$; Fig. $8 \mathrm{a})$, the expression of the iNOS2 gene showed significant increases in the LC of transgenic animals during basal conditions $(P<0.01$;
Fig. 8c). However, after the exposure to repeated stress, TNF- $\alpha$ mRNA levels were reduced compared to corresponding wild-type rats $(P<0.05$; Fig. $8 \mathrm{a})$, while gene expression of iNOS2 was significantly reduced in repeatedly stressed transgenic rats when compared to unstressed transgenic rats $(P<0.05$; Fig. $8 \mathrm{c})$.

Gene expression of the anti-inflammatory cytokine IL-10 was significantly elevated during basal conditions in the LC of transgenic rats $(P<0.01$; Fig. $8 \mathrm{~b})$. Even if stress had no effect on IL-10 mRNA levels in transgenic rats, gene expression of IL-10 was significantly elevated in both singly stressed and adapted IMO transgenic rats when compared to values found in corresponding wild-type animals $(P<0.05$; Fig. $8 \mathrm{~b})$.

Gene expression of neuroprotective factor TGF $\beta 1$ in wild-type animals was not affected by stress. However, TGF $\beta 1$ mRNA levels were significantly lower in repeatedly stressed and adapted IMO transgenic rats compared 


\section{Cornu ammonis}
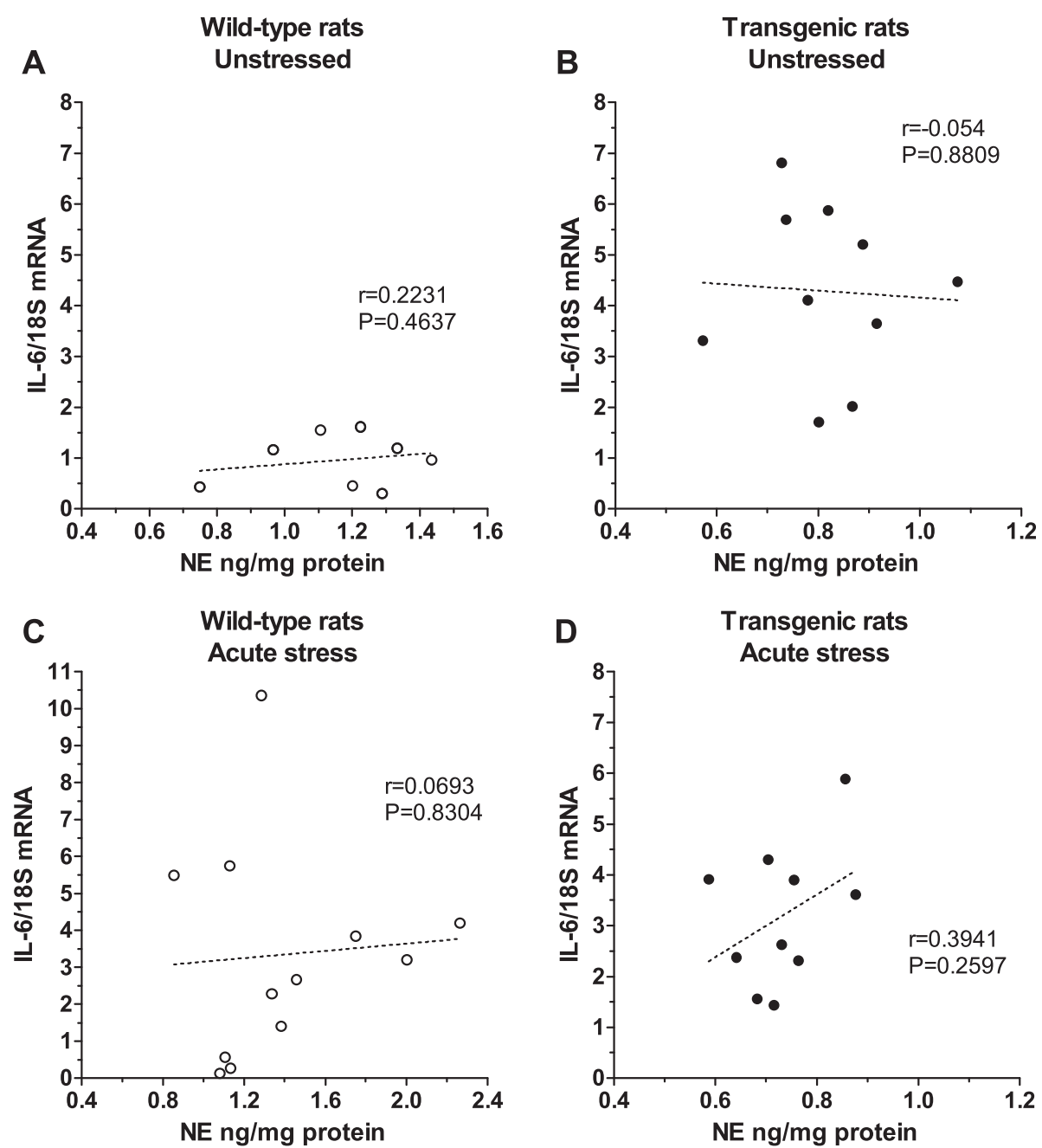

Fig. 9 Correlation plots illustrating the relationship of norepinephrine (NE) concentration and interleukine-6 mRNA (IL-6 mRNA) in cornu ammonis (CA) of wild-type controls (a, white circle), transgenic controls (b, black circle), wild-type rats exposed to a single 2-h immobilization stress (c, white circle), and transgenic rats exposed to a single 2-h immobilization stress (d, black circle)

to levels found in the corresponding wild-type animals $(P<0.05$; Fig. 8d).

\section{Effect of tauopathy on correlation between} norepinephrine and IL-6 mRNA levels in cornu ammonis under basal and stress conditions

The reduced NE and elevated IL- 6 mRNA levels found in unstressed transgenic rats (Fig. 3), differences in NE and IL-6 mRNA levels in stressed transgenic animals (Figs. 4, 5, and 6), and altered immune background in the LC (Fig. 8) indicate the effect of deregulated immunomodulation on the brain's noradrenergic system. Therefore, we investigated the effect of stress in both wild-type and transgenic rats on the relationship between NE and IL-6 mRNA levels in the CA, a brain structure innervated almost exclusively by the LC.
We did not find any correlation between NE and IL-6 mRNA levels in the CA of either unstressed or stressed wild-type (Fig. 9a, c) or transgenic rats (Fig. 9b, d). However, whereas NE levels are similar between unstressed wild-type and transgenic rats (ranging from 0.7 to $1.5 \mathrm{ng} / \mathrm{mg}$ of protein), the mean gene expression of IL-6 is almost three times higher in transgenic rats (Fig. 9a, b).

\section{Discussion}

The brain's noradrenergic system regulates the central stress response [23] and maintains several cognitive, affective, and behavioral functions [3, 24], while contributing to the consolidation of learning and memory [25]. However, Gibbs and Summers showed that NE released by brainstem noradrenergic neurons, besides its neurotransmitter role, is also involved in maintaining the 
brain's tissue milieu [4]. Furthermore, centrally released NE modulates synaptic plasticity, neurogenesis, energy metabolism, activity of astrocytes and microglia, cortical perfusion, and the permeability of the blood-brain barrier [4-7]. Moreover, it also exerts several potent anti-inflammatory and anti-oxidative effects on the brain tissue [26]. All of the abovementioned "homeostatic" processes modulated by NE are impaired in the brains of AD patients. Importantly, recent findings of Braak et al. [9] indicate that in humans, pathological tau species are originally formed in the LC (the brainstem structure representing the main accumulation of noradrenergic neurons in the brain) and then spread by axonal transport and interneuronal communications to the transentorhinal region, then to the entorhinal region, the hippocampal formation, and then later to the association cortices [9]. Therefore, it is suggested that the LC plays a crucial role in the development of AD-related neuropathology [11]. The importance of the $\mathrm{LC}$ in $\mathrm{AD}$ development is further supported by the finding that LC destruction results in the worsening of neuroinflammation and amyloid $\beta$ deposition in brains of transgenic $\mathrm{A} \beta$ animal models, as well as in elevated IL-1 $\beta$ and $\mathrm{Ccl} 2$ cytokines in laboratory animals $[27,28]$. Interestingly, monoaminergic deficiency and severe depletion of $\mathrm{NE}$ has been found in most LC projection areas in AD patients [29]. Morphological studies of brains of AD patients have shown that the LC undergoes significant degeneration that precedes pathological changes in the forebrain [30]. It is suggested that this degeneration starts early in the course of AD pathogenesis and that the LC represents the centre from which altered tau proteins spread throughout the forebrain structures [9]. Therefore, we investigated the effect of tauopathy on the LC by using transgenic (SHR72) rats that over-express human truncated tau protein [17].

Preclinical investigation of the LC role in AD pathogenesis is based mainly on the study of the effects resulting from the destruction of this noradrenergic cell group on the development of AD-related neuropathology. However, in the available literature, information on tauopathy's effect on LC functions and on the immune background of brain tissue during basal and stress conditions is lacking.

Based on the abovementioned facts, we investigated the mutual relationship between the brain's noradrenergic system and immune activity in unstressed and singly or repeatedly stressed wild-type and transgenic rats that over-express human truncated tau protein [17]. Here, we demonstrate for the first time that expression of human truncated tau protein, whose primary sequence was derived from paired helical filaments obtained from the brains of AD patients, is sufficient to induce dysfunction of LC neurons in vivo and this dysfunction is most likely followed by exaggerated synthesis of pro-inflammatory cytokines in brain structures innervated by the LC that are known to be affected by neuropathology in AD patients.

We have found significant reduction of basal NE levels in hippocampus (CA and DG) and NBM as well as in cortical areas (frontal and temporal association cortex) of transgenic rats, structures innervated almost entirely by noradrenergic LC neurons [3]. Our findings indicate that the function of the noradrenergic system in the brains of transgenic rats is significantly impaired, at least at the level of NE synthesis. This is in agreement with observed significant reductions of NE levels on the cerebrospinal fluid of $\mathrm{AD}$ patients compared to matched controls [31].

Recent studies have revealed that NE exerts a potent anti-inflammatory effect on the brain [32]. In support of this, decreased cerebral NE levels and exacerbated neuroinflammatory processes have been demonstrated in murine AD models [27, 33]. Moreover, it is suggested that the reduction of $\mathrm{LC}$ noradrenergic neurons in the brains of $\mathrm{AD}$ patients could be one factor responsible for the exaggerated neuroinflammation in the brains of these patients [34]. Based on these facts and assumptions, the question has been raised as to whether the reduction of brain's tissue NE levels in transgenic (SHR72) rats is accompanied by altered immune status in the brain of these animals. Therefore, we analyzed the gene expression of IL-6, one of the main immune system factors in the brain [35]. In transgenic rats, we found a significant elevation of IL-6 mRNA in CA, DG, and FCx. Moreover, significantly elevated IL-6 mRNA levels were also found in the brainstem, particularly in the LC, A1, and A2 noradrenergic cell groups. Increased gene expression of IL-6 in forebrain structures may reflect the reduced anti-inflammatory effect of NE due to reduced NE concentrations in these forebrain areas, while the increased IL-6 mRNA levels in brainstem noradrenergic areas may result from the burden of tau pathology, as it is localized mainly in the brainstem of transgenic (SHR72) rats [16].

It is suggested that stress represents important factor participating in the development of $\mathrm{AD}$ (for review, see [12]). Moreover, AD-related neuropathology may affect the stress response as well [36]. Because the LC represents a key structure modulating stress responses in the brain [23] and that we found that tauopathy impairs LC function, we investigated the effect of single and repeated stress on tissue levels of NE against the background of tauopathy. Interestingly, the exposure of transgenic rats to stress did not significantly affect NE levels when compared to unstressed transgenic animals. However, in the CA, DG, FCx, and NBM, NE levels in transgenic animals were significantly lower when compared to the NE levels of corresponding wild-type groups. These findings indicate that tauopathy reduces noradrenergic neurotransmission 
not only at basal conditions but also in animals exposed to stressors. Furthermore, these reduced NE levels in the forebrain areas of stressed, transgenic rats were accompanied by elevated gene expression of IL- 6 in the CA and DG. Moreover, IL-6 mRNA levels were also elevated in brainstem A1 noradrenergic cells of stressed, transgenic animals. These findings indicate that the immune milieu remains altered in investigated brain areas in stressed, transgenic rats, but stress is not able to significantly affect gene expression of IL-6. It can be speculated that exposure to immobilization stress daily for 7 days is not sufficient to alter the immune status of transgenic rats and therefore longer period of chronic stress exposure will be necessary to determine the effect of stress on neuroinflammation at the background of tauopathy.

In transgenic (SHR72) rats, tau pathology is predominantly found in the brainstem [16]. However, even if reduced NE levels in forebrain areas of transgenic rats indicate functional impairment of the $\mathrm{LC}$, we did not find any neurodegenerative changes at the level of the LC morphology (unpublished data). Using immunohistochemistry, we found accumulation of tau pathology in the form of AT8-immunopositive tau, pre-tangles, and neurofibrillary tangles in brainstem areas that innervate the LC, particularly in the paragigantocellular nucleus and hypoglossal preposite nucleus (unpublished data). Neurons of the paragigantocellular nucleus project to the LC and increase noradrenergic neurotransmission in many forebrain areas, including the hippocampus, via mostly glutamatergic excitatory fibers [37]. Therefore, we speculate that in transgenic (SHR72) rats, the tauopathy found in the paragigantocellular nucleus attenuates glutamatergic neurotransmission from the LC, which consequently reduces levels of NE in forebrain structures. However, alternative mechanisms may participate in the impairment of the $\mathrm{LC}$ as well, including reduced axonal transport of trophic factors to the nuclei of LC neurons from structures innervated by the LC.

To further investigate the functional impairment of the LC, we determined gene expression and protein levels of $\mathrm{TH}$, the rate-limiting enzyme of NE biosynthesis as TH mRNA levels reflect changes in activity of the noradrenergic cells in this brain area [23]. We detected a significant increase of TH mRNA in the LC of repeatedly stressed wild-type animals that is in accordance with our previous reports [23, 38-41]. Importantly, $\mathrm{TH}$ protein concentration in the $\mathrm{LC}$ is in good agreement with $\mathrm{TH}$ expression. When compared to wild-type rats, transgenic (SHR72) animals started from the higher basal levels of TH mRNA, but did not show any significant changes after stress exposure. Increased $\mathrm{TH}$ levels in transgenic rats indicate exaggerated NE biosynthesis. However, as discussed above, NE levels in forebrain areas innervated by the LC were reduced. There is published data showing that even if the number of LC neurons in the brain of AD patients is significantly reduced, the remaining LC neurons undergo significant compensatory changes [42]. Our contradictory findings indicate that even if compensatory mechanisms in noradrenergic neurotransmission machinery are activated at the level of the LC, these responses are not able to compensate for the functional deficits manifested by reduced NE concentrations in brain areas innervated by the LC.

Besides the LC, we also analyzed TH mRNA in other noradrenergic cell groups that participate in noradrenergic innervation of forebrain structures, particularly in the A1 and A2 noradrenergic cell groups. However, in contrast to the $\mathrm{LC}$, the A1 and A2 noradrenergic cell groups predominantly innervate the hypothalamus [23]. Therefore, sparse information is available as to how neurofibrillary pathology affects these cell groups. We found that TH mRNA levels in wild-type animals were significantly elevated in A1 and A2 noradrenergic cell groups after repeated stress. Also, while TH mRNA in A1 noradrenergic cells group of transgenic rats started from elevated basal levels, no further changes were detected after either single or repeated stress. We suggest that similarly to $\mathrm{LC}$, increased $\mathrm{TH}$ expression in the A1 noradrenergic cell group might represent a compensatory response to impairment of $\mathrm{TH}$-positive A1 neurons in this transgenic (SHR72) animal model of tauopathy. However, AD-related neuropathology of A1 noradrenergic neurons has not yet been described in available literature. However, we found that the A2 noradrenergic cell group shows an increase of TH mRNA levels in repeatedly stressed wild-type animals not seen in transgenic rats. Because the $\mathrm{A} 1$ and $\mathrm{A} 2$ noradrenergic cell groups innervate mainly the hypothalamic nuclei, we also investigated changes in NE level in the hypothalamic paraventricular nucleus. Importantly, in contrast to significantly reduced NE levels in forebrain structures innervated by the LC, we found that NE levels were only non-significantly reduced in the hypothalamic paraventricular nucleus in transgenic rats $(9.93 \pm 0.94 \mathrm{ng} / \mathrm{mg}$ protein) compared to wild-type animals $(16.38 \pm 2.57 \mathrm{ng} / \mathrm{mg}$ protein). These findings indicate that tauopathy in transgenic (SHR72) rats affects predominantly noradrenergic neurotransmission in the hippocampus, nucleus basalis of Meynert, and association cortices, all of which are areas innervated by the LC and affected in AD patients.

To further to determine the mechanisms responsible for tau-related alteration of the $\mathrm{LC}$ in transgenic (SHR72) rats, we measured tissue mRNA levels of both pro- and anti-inflammatory factors, including TNF- $\alpha$, iNOS2, IL-10, and TGF 31 . We found that gene expression of these factors differs between wild-type and transgenic rats at both basal and stressed conditions, although TNF- $\alpha$ mRNA levels in unstressed, transgenic rats were only 
non-significantly increased. However, even if gene expression of TNF- $\alpha$ declined in repeatedly stressed transgenic rats compared to unstressed transgenic rats, TNF- $\alpha$ mRNA in rats exposed to repeated stress was significantly elevated compared to the matched, wild-type group. Gene expression of iNOS2, another pro-inflammatory factor, was significantly increased at basal conditions and findings related to gene expression of TNF- $\alpha$ and iNOS2 indicate a pro-inflammatory milieu in the LC tissue of transgenic rats. Moreover, gene expression of the anti-inflammatory cytokine IL-10 was increased in unstressed transgenic rats as well as in transgenic animals exposed to a single stressor, indicating activation of compensatory immune mechanisms at the level of the LC against a background of tauopathy. Comparison of NE, IL- 6 mRNA, TNF- $\alpha$ mRNA, and IL-10 mRNA in the LC of transgenic rats indicate that the anti-inflammatory effect of NE in the LC is impaired. Because tauopathy is localized predominantly to the brainstem of transgenic (SHR72) rats, several local factors may promote an inflammatory milieu in the LC as well. Reduced gene expression of the neuroprotective factor TGF $\beta 1$ in repeatedly stressed transgenic rats highlights impairment of neuroprotective mechanisms in the LC. Based on the abovementioned findings, we suggest that tauopathy affects function of brainstem nuclei innervating the LC and alters the brainstem immune milieu. These alterations might participate in neuroinflammation and the reduced neuroprotection in the LC accompanied by reduced release of NE by LC neurons into the forebrain areas of transgenic (SHR72) rats. Reduced NE release might then participate in the development of neuroinflammation in forebrain structures innervated by the LC.

To investigate the role of the LC dysfunction in observed alteration of immune milieu in forebrain areas of transgenic rats, we assessed the correlation between NE and IL- 6 mRNA levels in both wild-type and transgenic rats at basal and stress conditions. Importantly, we found that even if there was no correlation between NE and IL-6 mRNA levels at basal conditions, transgenic rats exhibit approximately threefold higher IL-6 mRNA levels. These findings indicate that the inhibitory effect of brain NE on neuroinflammation is severally impaired against a background of tauopathy. However, the mechanisms and pathways responsible for this phenomenon need further investigation.

It is necessary to note that all abovementioned parameters (e.g., interleukins) were investigated in brain tissues obtained by microdissection (punching) technique. However, this method does not allow to determine whether alterations are present in neurons, glia, or both types of cells. Therefore, for more complex view of neuropathological consequences of tau pathology on the function of the LC and on neuroinflammation, other approaches (e.g., immunohistochemistry) must be used.

\section{Conclusions}

Our data have shown that tau pathology in the brains of transgenic (SHR72) rats alters central noradrenergic neurotransmission, particularly in brain's structures innervated by noradrenergic neurons, under basal conditions as well as after an exposure to single or chronic stress. We observed increases in IL-6 gene expression in brain structures that may reflect a reduced anti-inflammatory effectiveness of the LC noradrenergic system. Importantly, some in vitro and in vivo studies have provided evidence that increases in NE levels can attenuate AD-related neuropathology and neuroinflammation, while enhancing cognition [43, 44]. In support of this, some clinical studies have already confirmed that pharmacotherapy potentiating noradrenergic neurotransmission is able to improve cognitive symptoms, while reducing depression and aggression in $\mathrm{AD}$ patients [45-47].

However, it is necessary to note that it remains unclear whether tauopathy in transgenic (SHR72) rats affect LC neurons directly or indirectly. Indirect mechanisms of altered LC function in transgenic rats may include (i) impaired transport of trophic factors from brainstem structures affected by tauopathy to the LC and (ii) reduced synthesis of norepinephrine in varicosities of the LC neurons as a result of either the pro-inflammatory milieu or other mechanisms. Moreover, tauopathy in transgenic (SHR72) rats may also potentially affect other catecholaminergic cell groups, exaggerating the noradrenergic deficit followed by impairment of the brain milieu and development of neuropathology. However, it is unclear whether other monoaminergic cell groups are affected in this transgenic model, and therefore, this needs further investigation.

Based on our data, we suggest that transgenic rats of this study can be efficiently employed in detailed investigation of molecular mechanisms of neuronal degeneration related to tauopathy, neuroinflammation, and, more importantly, in the development of disease modifying strategy for treatment of Alzheimer's disease and other tauopathies.

\section{Abbreviations \\ AD: Alzheimer's disease; CA: cornu ammonis; DG: dentate gyrus; FCx: frontal cortex; IL-10: interleukin 10; IL-6: interleukin 6; IMO: immobilization; \\ iNOS2: inducible nitric oxide synthases 2; LC: locus coeruleus; NBM: nucleus basalis of the Meynert; NE: norepinephrine; TCx: temporal cortex: \\ TGF $\beta 1$ : transforming growth factor beta 1; TH: tyrosine hydroxylase; TNF-a: tumor necrosis factor alpha.}

Competing interest

The authors declare that they have no competing interests.

\section{Authors' contributions}

$\mathrm{BM}, \mathrm{PF}$, and RK designed the experiments and supervised the project. $\mathrm{KL}, \mathrm{PV}, \mathrm{KO}, \mathrm{LH}$, and $\mathrm{PN}$ carried out the in vivo experiments. $\mathrm{KL}, \mathrm{PV}$, and $\mathrm{GM}$ carried out the molecular analyses. BM, PF, MN, and RK analyzed data and wrote the manuscript. All authors have read and approved the final version of the manuscript. 


\section{Acknowledgements}

This work was supported by the Slovak Research and Development Agency under the contracts no. APW-0088-10 and APV-0677-12, BrainCentrum 2013-2014, and by grant VEGA 2/0067/14.

\section{Author details}

'Institute of Experimental Endocrinology, Slovak Academy of Sciences, Vlarska 3, 83306 Bratislava, Slovakia. ${ }^{2}$ Institute of Physiology, Faculty of Medicine, Comenius University in Bratislava, Bratislava, Slovakia. Institute of Neuroimmunology, Slovak Academy of Sciences, Bratislava, Slovakia. ${ }^{4}$ Axon Neuroscience SE, Bratislava, Slovakia. ${ }^{5} \mathrm{LDN}$, Labor Diagnostika Nord, Nordhorn, Germany.

Received: 29 June 2015 Accepted: 13 January 2016 Published online: 20 January 2016

\section{References}

1. Ramanan VK, Saykin AJ. Pathways to neurodegeneration: mechanistic insights from GWAS in Alzheimer's disease, Parkinson's disease, and related disorders. Am J Neurodegener Dis. 2013;2(3):145-75.

2. Armstrong RA. What causes Alzheimer's disease? Folia Neuropathol. 2013:51(3):169-88. doi:21432 [pii].

3. Benarroch EE. The locus ceruleus norepinephrine system: functional organization and potential clinical significance. Neurology. 2009;73(20):1699-704 doi:10.1212/WNL.0b013e3181c2937c.

4. O'Donnell J, Zeppenfeld D, McConnell E, Pena S, Nedergaard M. Norepinephrine: a neuromodulator that boosts the function of multiple cell types to optimize CNS performance. Neurochem Res. 2012;37(11):2496-512. doi:10.1007/s11064-012-0818-x.

5. Hertz L, Lovatt D, Goldman SA, Nedergaard M. Adrenoceptors in brain: cellular gene expression and effects on astrocytic metabolism and $[\mathrm{Ca}(2+)] \mathrm{i}$. Neurochem Int. 2010;57(4):411-20. doi:10.1016/j.neuint.2010.03.019.

6. Marien MR, Colpaert FC, Rosenquist AC. Noradrenergic mechanisms in neurodegenerative diseases: a theory. Brain Res Brain Res Rev. 2004;45(1):38-78. doi:10.1016/j.brainresrev.2004.02.002. S0165017304000165 [pii].

7. Toussay X, Basu K, Lacoste B, Hamel E. Locus coeruleus stimulation recruits a broad cortical neuronal network and increases cortical perfusion. J Neurosci. 2013;33(8):3390-401. doi:10.1523/JNEUROSCI.3346-12.2013.

8. Clavaguera F, Hench J, Goedert M, Tolnay M. Invited review: Prion-like transmission and spreading of tau pathology. Neuropathol Appl Neurobiol. 2015:41(1):47-58. doi:10.1111/nan.12197.

9. Braak H, Thal DR, Ghebremedhin E, Del Tredici K. Stages of the pathologic process in Alzheimer disease: age categories from 1 to 100 years. J Neuropathol Exp Neurol. 2011:70(11):960-9. doi:10.1097/NEN.0b013e318232a379.

10. Pamphlett R, Kum JS. Different populations of human locus ceruleus neurons contain heavy metals or hyperphosphorylated tau: implications for amyloid-beta and tau pathology in Alzheimer's disease. J Alzheimers Dis. 2015:45(2):437-47. doi:10.3233/JAD-142445. 130X574785821T62 [pii].

11. Mravec B, Lejavova K, Cubinkova V. Locus (coeruleus) minoris resistentiae in pathogenesis of Alzheimer's disease. Curr Alzheimer Res. 2014;11(10):992-1001. doi:CAR-EPUB-63259 [pii].

12. Machado A, Herrera AJ, de Pablos RM, Espinosa-Oliva AM, Sarmiento M, Ayala $A$, et al. Chronic stress as a risk factor for Alzheimer's disease. Rev Neurosci. 2014;25(6):785-804. doi:10.1515/revneuro-2014-0035/j/revneuro. ahead-of-print/revneuro-2014-0035/revneuro-2014-0035.xml [pii].

13. Ricci S, Fuso A, Ippoliti F, Businaro R. Stress-induced cytokines and neuronal dysfunction in Alzheimer's disease. J Alzheimers Dis. 2012;28(1):11-24. doi:10.3233/JAD-2011-110821.

14. Carroll JC, Iba M, Bangasser DA, Valentino RJ, James MJ, Brunden KR, et al. Chronic stress exacerbates tau pathology, neurodegeneration, and cognitive performance through a corticotropin-releasing factor receptor-dependent mechanism in a transgenic mouse model of tauopathy. J Neurosci. 2011:31(40):14436-49. doi:10.1523/JNEUROSCI.3836-11.2011.

15. Marcello E, Gardoni F, Di Luca M. Alzheimer's disease and modern lifestyle: what is the role of stress? J Neurochem. 2015;134(5):795-8. doi:10.1111/jnc.13210.

16. Zilka N, Filipcik P, Koson P, Fialova L, Skrabana R, Zilkova M, et al. Truncated tau from sporadic Alzheimer's disease suffices to drive neurofibrillary degeneration in vivo. FEBS Lett. 2006;580(15):3582-8. doi:10.1016/j.febslet.2006.05.029.

17. Koson P, Zilka N, Kovac A, Kovacech B, Korenova M, Filipcik P, et al. Truncated tau expression levels determine life span of a rat model of tauopathy without causing neuronal loss or correlating with terminal neurofibrillary tangle load. Eur J Neurosci. 2008;28(2):239-46. doi:10.1111/j.1460-9568.2008.06329.x

18. Stozicka Z, Zilka N, Novak P, Kovacech B, Bugos O, Novak M. Genetic background modifies neurodegeneration and neuroinflammation driven by misfolded human tau protein in rat model of tauopathy: implication for immunomodulatory approach to Alzheimer's disease. J Neuroinflammation. 2010;7:64. doi:10.1186/1742-2094-7-64.

19. Kvetnansky R, Mikulaj L. Adrenal and urinary catecholamines in rats during adaptation to repeated immobilization stress. Endocrinology. 1970;87(4):738-43. doi:10.1210/endo-87-4-738.

20. Palkovits M. Isolated removal of hypothalamic or other brain nuclei of the rat. Brain Res. 1973;59:449-50. doi:0006-8993(73)90290-4 [pii].

21. Palkovits M, Brownstein MJ. Maps and quide to microdissection of the rat brain. New York: Elsevier Science Publishing Co; 1988.

22. Livak KJ, Schmittgen TD. Analysis of relative gene expression data using real-time quantitative PCR and the 2(-Delta Delta C(T)) Method. Methods. 2001:25(4):402-8. doi:10.1006/meth.2001.1262S1046-2023(01)91262-9 [pii].

23. Kvetnansky R, Sabban EL, Palkovits M. Catecholaminergic systems in stress: structural and molecular genetic approaches. Physiol Rev. 2009;89(2):535-606. doi:10.1152/physrev.00042.2006.

24. Herrmann N, Lanctot $K L$, Khan LR. The role of norepinephrine in the behavioral and psychological symptoms of dementia. J Neuropsychiatry Clin Neurosci. 2004;16(3):261-76. doi:10.1176/appi.neuropsych.16.3.26116/3/261 [pii].

25. Gibbs ME, Summers RJ. Role of adrenoceptor subtypes in memory consolidation. Prog Neurobiol. 2002;67(5):345-91. doi:S0301008202000230 [pii].

26. Feinstein DL, Heneka MT, Gavrilyuk V, Dello Russo C, Weinberg G, Galea E. Noradrenergic regulation of inflammatory gene expression in brain. Neurochem Int. 2002;41(5):357-65. doi:S0197018602000499 [pii].

27. Heneka MT, Nadrigny F, Regen T, Martinez-Hernandez A, Dumitrescu-Ozimek L, Terwel D, et al. Locus ceruleus controls Alzheimer's disease pathology by modulating microglial functions through norepinephrine. Proc Natl Acad Sci U S A. 2010;107(13):6058-63. doi:10.1073/pnas.0909586107.

28. Jardanhazi-Kurutz D, Kummer MP, Terwel D, Vogel K, Thiele A, Heneka MT. Distinct adrenergic system changes and neuroinflammation in response to induced locus ceruleus degeneration in APP/PS1 transgenic mice. Neuroscience. 2011;176:396-407. doi:10.1016/j.neuroscience.2010.11.052

29. Matthews KL, Chen CP, Esiri MM, Keene J, Minger SL, Francis PT. Noradrenergic changes, aggressive behavior, and cognition in patients with dementia. Biol Psychiatry. 2002;51(5):407-16.

30. Trillo L, Das D, Hsieh W, Medina B, Moghadam S, Lin B, et al. Ascending monoaminergic systems alterations in Alzheimer's disease. Translating basic science into clinical care. Neurosci Biobehav Rev. 2013;37(8):1363-79. doi:10.1016/j.neubiorev.2013.05.008.

31. Kaddurah-Daouk R, Rozen S, Matson W, Han X, Hulette CM, Burke JR, et al. Metabolomic changes in autopsy-confirmed Alzheimer's disease. Alzheimers Dement. 2011;7(3):309-17. doi:10.1016/j.jalz.2010.06.001

32. Chavarria A, Cardenas G. Neuronal influence behind the central nervous system regulation of the immune cells. Front Integr Neurosci. 2013;7:64. doi:10.3389/fnint.2013.00064

33. Heneka MT, Galea E, Gavriluyk V, Dumitrescu-Ozimek L, Daeschner J, O'Banion MK, et al. Noradrenergic depletion potentiates beta -amyloid-induced cortical inflammation: implications for Alzheimer's disease. J Neurosci. 2002:22(7):2434-42

34. Eikelenboom P, van Exel E, Hoozemans JJ, Veerhuis R, Rozemuller AJ, van Gool WA. Neuroinflammation - an early event in both the history and pathogenesis of Alzheimer's disease. Neurodegener Dis. 2010;7(1-3):38-41. doi:10.1159/000283480.

35. Erta M, Quintana A, Hidalgo J. Interleukin-6, a major cytokine in the central nervous system. Int J Biol Sci. 2012;8(9):1254-66. doi:10.7150/ijbs. 4679ijbsv08p1254 [pii].

36. Lejavova K, Ondicova K, Horvathova L, Hegedusova N, Cubinkova V, Vargovic $P$, et al. Stress-induced activation of the sympathoadrenal system is determined by genetic background in rat models of tauopathy. J Alzheimers Dis. 2015:43(4):1157-61. doi:10.3233/JAD-141329.

37. Mello-Carpes PB, Izquierdo I. The nucleus of the solitary tract $\rightarrow$ nucleus paragigantocellularis $\rightarrow$ locus coeruleus $\rightarrow$ CA1 region of dorsal hippocampus pathway is important for consolidation of object recognition memory. Neurobiol Learn Mem. 2013;100:56-63. doi:10.1016/..nlm.2012.12.002.

38. Sabban EL, Kvetnansky R. Stress-triggered activation of gene expression in catecholaminergic systems: dynamics of transcriptional events. Trends Neurosci. 2001;24(2):91-8. doi:S0166-2236(00)01687-8 [pii]. 
39. Sabban EL. Catecholamines in stress: molecular mechanisms of gene expression. Endocr Regul. 2007;41(2-3):61-73.

40. Kvetnansky R, Sabban EL. Stress and molecular biology of neurotransmitterrelated enzymes. Ann N Y Acad Sci. 1998;851:342-56.

41. Mravec B, Vargovic P, Filipcik P, Novak M, Kvetnansky R. Effect of a single and repeated stress exposure on gene expression of catecholamine biosynthetic enzymes in brainstem catecholaminergic cell groups in rats. Eur J Neurosci. 2015.

42. Szot P, White SS, Greenup JL, Leverenz JB, Peskind ER, Raskind MA Compensatory changes in the noradrenergic nervous system in the locus ceruleus and hippocampus of postmortem subjects with Alzheimer's disease and dementia with Lewy bodies. J Neurosci. 2006;26(2):467-78. doi:10.1523/JNEUROSCI.4265-05.2006.

43. Yang JH, Lee EO, Kim SE, Suh YH, Chong YH. Norepinephrine differentially modulates the innate inflammatory response provoked by amyloid-beta peptide via action at beta-adrenoceptors and activation of CAMP/PKA pathway in human THP-1 macrophages. Exp Neurol. 2012;236(2):199-206. doi:10.1016/j.expneurol.2012.05.008S0014-4886(12)00206-3 [pii].

44. Counts SE, Mufson EJ. Noradrenaline activation of neurotrophic pathways protects against neuronal amyloid toxicity. J Neurochem. 2010;113(3):649-60. doi:10.1111/j.1471-4159.2010.06622.xJNC6622 [pii].

45. Shankle WR, Nielson KA, Cotman CW. Low-dose propranolol reduces aggression and agitation resembling that associated with orbitofrontal dysfunction in elderly demented patients. Alzheimer Dis Assoc Disord. 1995:9(4):233-7.

46. Reifler BV, Teri L, Raskind M, Veith R, Barnes R, White E, et al. Double-blind trial of imipramine in Alzheimer's disease patients with and without depression. Am J Psychiatry. 1989;146(1):45-9.

47. Riekkinen Jr P, Riekkinen M. THA improves word priming and clonidine enhances fluency and working memory in Alzheimer's disease. Neuropsychopharmacology. 1999;20(4):357-64. doi:10.1016/50893-133X(98)00093-1.

48. Max MB, Stewart WF. The molecular epidemiology of pain: a new discipline for drug discovery. Nat Rev Drug Discov. 2008;7(8):647-58. doi:10.1038/nrd2595.

49. Paxinos $G$, Watson C. The rat brain in stereotaxic coordinates. New York: Academic; 1997.

\section{Submit your next manuscript to BioMed Central and we will help you at every step:}

- We accept pre-submission inquiries

- Our selector tool helps you to find the most relevant journal

- We provide round the clock customer support

- Convenient online submission

- Thorough peer review

- Inclusion in PubMed and all major indexing services

- Maximum visibility for your research

Submit your manuscript at www.biomedcentral.com/submit 